\title{
HAS PALAEONTOLOGY ANSWERS FOR SOME CURRENT ENVIRONMENTAL PROBLEMS?
}

\author{
Miquel DE RENZI \\ Institut Cavanilles. Universitat de Valencia. Apartado 2085. Valencia, E-4607I \\ Spain. e-mail: miquel.de.renzi@uv.es
}

De Renzi, M. 2001. Has palaeontology answers for some current environmental problems? [¿Tiene la paleontología claves para algunos de los problemas ambientales actuales?] Revista Española de Paleontología, $\mathbf{n}^{0}$ extraordinario, 5-14. ISSN 0213-6937.

\begin{abstract}
History as an irreversible process has no role from a uniformitarian point of view in geology and palaeobiology. Contingency is another trait of history and particle palaeontology has its foundation on such principles. However, new approaches in physics and the theory of systems point out the need to consider a time arrow. Moreover, chance and necessity are interwoven in synergetics and self-organization theory and there may be some possibility of prediction. The global biota has a history resulting from a process of self-organization. A rich fossil record was produced during the Phanerozoic times and this fossil record shows us how life overcame several important crisis. A clear understanding of systems theory is required to understand these problems. On the other hand, there are species which are more prone to extinction than others. Although the physical environment plays an important role on the regulation of the global biota, the latter has an internal functioning with regulatory capability. Self-organised criticality seems a non negligible factor in extinction. The present situation of the global biota can be compared with others as illustrated by the fossil record. This can help us attack the environmental problems affecting us.
\end{abstract}

Keywords: Extinction, dynamical systems, chaos, self-organised criticality, extinction vulnerability, environment, Gaia hypothesis.

\section{RESUMEN}

En una concepción uniformista de la geología y de la paleobiología, la historia como proceso irreversible no juega ningún papel. La contingencia es un rasgo de la historia y la particle palcieontology tiene su fundamento sobre dichos principios. Sin embargo, los nuevos enfoques de la física y la teoría de sistemas apuntan a la necesidad de considerar la flecha del tiempo. Además, azar y necesidad están entrelazados en la sinergética y en la teoría de la autoorganización; la predicción entonces es posible de alguna manera. La biota global tiene una historia resultante de un proceso de autoorganización. Un rico registro fósil se produjo durante el Fanerozoico. Éste nos muestra cómo la vida superó varias crisis importantes. Se requiere un buen conocimiento de la teoría de sistemas para comprender estos problemas. Por otra parte, existen especies que están más abocadas que otras a la extinción. Aunque el ambiente físico juega un papel importante en la regulación de la biota global, esta última tiene un funcionamiento interno, también con capacidad reguladora. El estado crítico autoorganizado parece un factor de extinción del cual no se debe prescindir. El estado actual de la biota global se puede comparar con otros, tal como los ilustra el registro fósil. Esto puede sernos de ayuda a fín de abordar los problemas ambientales que nos afectan.

Palabras clave: Extinción, sistemas dinámicos, caos, estado crítico autoorganizado, vulnerabilidad a la extinción, medio ambiente, hipótesis de Gaia.

\section{INTRODUCTION}

Today, special attention is paid to systemic points of view in such different fields such as morphological evolution or taphonomy (e.g. see the invited lectures by Seilacher, 1991a; Alberch, 1991 and Fernández López,
1991 during the V Jornadas de Paleontologia). This perspective was not surprising, because it was already present in many palaeobiological papers published between 1970 and 1990. Although reductionism could have value as a methodological position, its Cartesian and Newtonian mechanistic paradigm is not generally suitable 


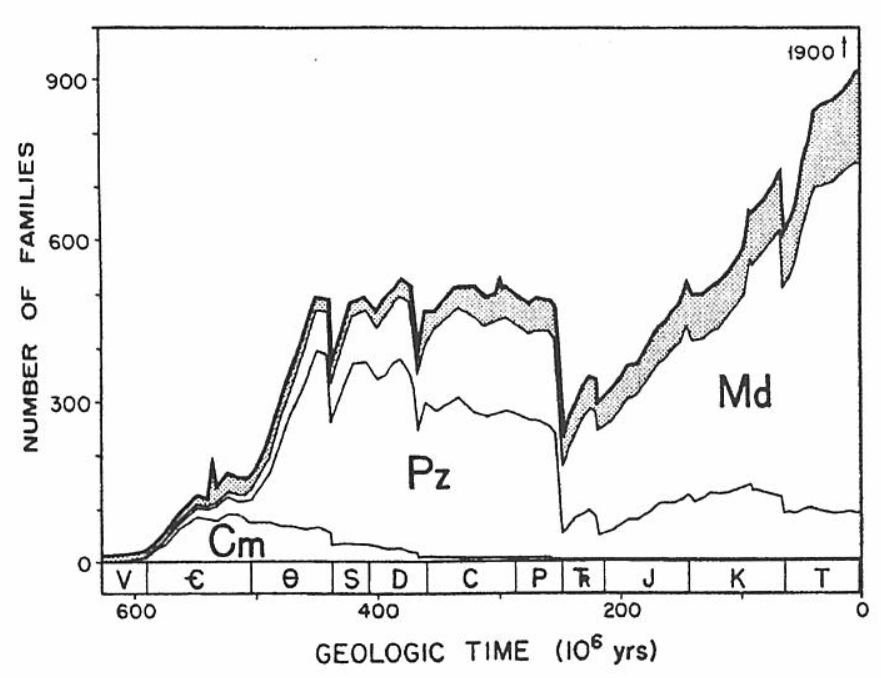

Figure 1. Sepkoski's evolutionary faunas. Cm, Cambrian fauna; $P z$, Palaeozoic fauna; $M d$, Modern fauna. From Sepkoski (1984).

for understanding the complex natural systems. Now, palaeontology can supply its own approach to critical problems preoccupying mankind. We are a part of the biosphere as a living species with multiple connections with other species and the physical environment; i.e. we belong to a larger system, in which actions in one part of it can result in enormous alterations in others. Palaeontology's contributions to these problems have to start from a systemic, non reductionist conception and this sets the need for criticising the uniformity principle.

The seventies were years of conflict between uniformitarian and pro-historical positions. History is intended as directional change and this has no meaning in a Lyellian sense. However, Lyell's ahistorical point of view -uniformitarianism involves no time arrow; nature remains uniform through time- is as dogmatic as biblical geology as supported by Buckland and others. This is a consequence of his substantive uniformitarianism. Although Lyell wanted to give up the biblical approach to geology in order to gain respectability and independence for this science, ironically he fell into a more theological and metaphysical principle. Substantive uniformitarianism could be at best a good null hypothesis, not a law of nature (Hooykaas, 1970). The only valid principle would be methodological uniformitarianism, whose assumptions call on induction and simplicity. However, this mode of thinking is common to any science and it is therefore not necessary as a specific principle for the historical sciences of earth or life (Gould, 1967).

Since Lyell's uniformity removes any time arrow, past and present are no different in character. Thus, any time would be adequate for any situation and any taxon throughout history of life on the earth (Gould et al., 1977); therefore, species could be considered as gas molecules in the biota receptacle, a theoretical proposal called particle palaeontology (Schopf, 1979). These authors claimed to give nomothetic status to palaeontology with this assumption. This model for life would borrow some features of statistical mechanics, since nothing can be said about any specific molecule of a gas mass enclosed in a recipient. There is a basic problem of prediction, although macroscopic averages can be predicted for the collective of molecules or particles. Palaeontologists are concerned with history and history is contingent. However, the point of view of particle palaeontology leads contingency towards the total impossibility of prediction.

On the other hand, the time arrow could be associated with progress. A sound reserve prevents us from admitting such vectors in history, although this reserve has an ideological component at heart. Thus, progress is refused because we are in the best of the possible worlds (Leibniz) or in a wisely designed world in perpetual steady state (Lyell). We cannot become engaged with such theological arguments. However, progress is also refused because this would involve changes improving our social system, an alibi in order to maintain the social system in its current situation (a return to the best of the worlds). Thus, determinism and progress are seen as two undesirable points of view, but ideological assumptions must not prevent us from dealing objectively with our scientific problems.

Therefore, contingency will be taken as a null hypothesis, as Raup (1977) suggested, but we ask for our capability to make some kinds of predictions; i.e. deterministic features of the living world in function of its past state. Extinction is one of the most remarkable phenomena common to both evolutionary palaeontology and social concerns about the environment. What does palaeontology teach us about extinction patterns? Sepkoski (1997) meant that detailed data about extinction and post-extinction recoveries would allow us to understand the recent and future behaviour of the modern biodiversity crisis. This information will be vital for people working in conservation biology. The extent of this and other similar assertions is the aim of this paper.

\section{SCIENCE OF SYSTEMS AND PALAEOBIOLOGY}

Newtonian philosophy of science appears at the foundation of Lyell's thinking for history of earth and life (Cabezas, 1998; for the influence of Herschell and Whewell on Lyell, see also Sequeiros, 1999). Moreover, it is also the foundation of the reductionist mind in science, by which a complex problem can be resolved by an adequate understanding of its separate aspects, something already existing in Descartes' philosophy. This reductionist approach is reflected in some views of recent literature in evolutionary palaeobiology. Several authors suggested that origination and extinction rates would be a product of chance in a global biota with limited resources. Taxonomic survival would exhibit loglineal patterns and evolutionary rates would become uniform in time. As a consequence, many features of evolution could be simulated as stochastic processes (Raup, 1977, 1981, 1985; Schopf, 1979). These simulations do not involve any kind of interaction among 
species. Chance generates morphological trends through simulations and species arise and become extinct in a piece-meal fashion, as Lyell thought about origination and extinction (Rudwick, 1972). However, large mass extinctions never appeared in these simulations. This was thought in accordance with background extinction and mass extinction as generated by different processes. The former would be a result of the internal functioning of the global biota, whereas the latter would be the product of an excessive supply of energy caused by a physical event (extraterrestrial impact, volcanic activity inducing climatic change, etc.). The uniform behaviour of the global biota would only be broken by abiotic environmental causes.

A different point of view was presented by Sepkoski $(1981,1984,1990,1993)$, who proposed a typical deterministic model in which he considered three marine evolutionary faunas: the Cambrian fauna, the Palaeozoic fauna and the Modern fauna that evolved in an interactive way (Fig. 1). The model consists of a set of three coupled logistic equations. Since each fauna depends on the other two in the model, a systemist position is adopted. In this model, origination and extinction rates are diversity dependent; therefore, they are not constant in time, although now these evolutionary faunas are not seen to be so individualised as the interactive model shows them (Miller, 1998). The marine biota would regulate itself; on the other hand, mass extinctions were not predicted by this model; they should be introduced as sudden increases of extinction rates.

Hoffman (1986) criticised this determinist point of view by saying the same pattern could be obtained by random simulation. However, Sepkoski's modellization was able to reproduce fine details of the geometry of natural diversification patterns. Furthermore, the model was not fully determinist, since Sepkoski attributed the increasing extinction rates influencing both Cambrian and Palaeozoic faunas to diffuse competition. Diffuse competition has a charge of random features. So, chance and necessity are interwoven, something relevant for many students of natural systems (Haken, 1983).

\section{SOME BASIC IDEAS OF SCIENCE OF SYSTEMS}

To begin with, what is a system? A system is a parcel of reality taken as an object and separate from the remaining world (its environment) (Bertalanffy, 1976; Klir, 1980). The essential point is that a system consists of interacting, non independent parts. This is in agreement with a more stronger proposition concerning the whole as different from the simple aggregation of its parts. Nature conceived of in this manner clashes with the Newtonian paradigm. When Georges Cuvier (fide Jacob, 1970) compared an organism with a machine, he was already aware of this. As he said, an organism could never be separated into its parts without killing it.

What is the boundary of a system? Organisms have very clear boundaries, but this is not the case for an ecosystem. Special cases such lakes or islands approach systems with definite boundaries, but they are the exception rather than the rule. Boundaries are fuzzy for the majority of natural systems. Finally, systems are composed of elements that arose in temporal or historical sequences. Interactions between elements of the same class can result in elements of a new class. Thus, each class of elements is a level of organization and each element of a level consists of interacting elements of the immediately precedent level in time. At each level, elements show two kinds of properties: emergent properties (they are not properties of the elements of the previous level, but they arise through its interaction) and additive properties (they are properties of the elements of the previous level or older levels). Levels of organization are hierarchically ordered. A hierarchical expansion of evolutionary theory has been proposed (Vrba and Eldredge, 1984; Buss, 1987; Vrba, 1989) with different levels: genomic components, cell lineage, organism, population, species and monophyletic group. Populations consist of organisms and organismal architecture is an additive property of the population, whereas the proportion of sexes or population size are emergent properties. The survival of a population depends on these two kinds of properties.

\section{FORMAL DESCRIPTION OF A SYSTEM}

How is a system described? A system is the result of a more or less elaborate abstraction (Klir, 1980). The second step is a formal description in quantitative terms. Attributes considered as relevant are quantified and their relevance is determined by experience. These traits can have something to do with different disciplines; e.g. force (physics), nutrients (chemistry) or population size (ecology). They are variables. There are spatial and temporal specifications for measures taken in a system, but atemporal relationships can also be obtained (see Klir, 1980). Thus, the classical allometric equation relating two variables $x$ and $y$ in a growing organism is an atemporal relationship; i.e. $y=a x^{b}$, in which $x$ and $y$ change exponentially, but time does not figure explicitly in the expression.

The essential question is how these variables change through time. However, spatial change could be important to control as well. In many cases, it is easier to analyse the rate of change of a variable. This leads directly to a classical mathematical tool: differential equations, whose use for attacking problems in physics has been proved successful since the XVIII' ${ }^{\text {th }}$ century. Differential equations assume time to be a continuous variable and we call them continuous dynamical systems. If time consists of discontinuous, discrete steps, it leads to difference equations (discrete dynamical systems) ( $\mathrm{Tu}$, 1994; Solé and Manrubia, 1996a). Here, we shall deal only with autonomous differential equations; i.e. in the form

$$
d y / d t=f(y \mid a)
$$

or autonomous difference equations 


$$
y_{t+1}=f\left(y_{t} \mid \boldsymbol{a}\right)
$$

( $\boldsymbol{a}$ is a set of parameters [vector] that remain constant in each specific case), in which the independent variable $t$ does not figure explicitly. If $f(y \mid \boldsymbol{a})$ or $f\left(y_{t} \mid \boldsymbol{a}\right)$ are expressed as $f_{1}\left(y \mid \boldsymbol{a}_{1}\right)+f_{2}\left(\boldsymbol{a}_{2}\right)$, they are inhomogeneous autonomous equations. If $f_{2}\left(\boldsymbol{a}_{2}\right)=0$, they are homogeneous autonomous equations. For the sake of simplify, now we write $d y / d t=y^{\prime}$.

Both differential or difference equations are useful because they allow prediction from specified initial conditions $t=t_{0}$ and $y=y_{0}$. Since a system requires more than one variable for its formal description, sets of equations are needed, one equation for each variable. Therefore,

$$
\text { or } \begin{aligned}
y_{i}^{\prime} & =f_{i}\left(y_{i} \mid \boldsymbol{a}\right) \\
y^{i}{ }_{t+1} & =f\left(y_{i}^{i}, \boldsymbol{a}\right)
\end{aligned}
$$

( $i=1, \ldots, n$, with $n$ as the number of variables considered).

The following considerations are valid for single equations or sets of equations. Both kinds can be linear or non linear (non linear means degree larger than 1 for $y$; e.g. $y^{2}$ ). The exponential law is represented by a linear differential equation such as $y^{\prime}=a y$, in which $y$ may mean population size or length of body, and $a$ is a parameter. Let $p$, be the genic frequency of an allel at the generation $t$. It is related to the gene frequency at the generation $t-1$ by the expression $p_{t}=p_{t-1}-m p_{t-1}(m$ is the mutation rate and the parameter of this equation). This is a linear difference equation. On the other hand, linear equations (or their sets) are related to the more reductionist features of science because they can have as solution any linear combination of solutions. In other words, the whole is the direct sum of its parts.

Although linear (differential or difference) equations are easy to deal with, natural systems are non linear in their behaviour. Exponential growth is more an exception than a rule. Populations or body magnitudes grow according to laws expressed by non linear equations. A very well known non linear differential equation is the logistic equation $y^{\prime}=r y\left(1-y / y_{m}\right)$, in which $y_{m}$ is a limit for the growth of $y$ and $r$ is the intrinsic growth rate; its degree is 2 since there is a term in $y^{2}$. Both $y_{m}$ and $r$ are parameters; $y$ may be population size, order diversity (as in the early model of Sepkoski, 1978) and so on. The logistic difference equation has received attention as well. A particular case has been considered as a paradigm in chaos theory as I shall comment below. This is

$$
y_{t+1}=a y_{t}\left(1-y_{t}\right) \text {, }
$$

with $a$ as a parameter. Linear equations admit analytical solutions whereas non linear equations do not generally admit them. Since the logistic equation admits analytical solution, it is one of the exceptions. Finally, linear combinations of particular solutions of non linear equations (or sets of equations) are not usually solutions for them. Hence, totalities are not direct sum of their parts and the Newtonian paradigm fails as methodological principle.

\section{STEADY STATES AND BIFURCATIONS}

Systems evolve in time. They may (or may not) reach a final state or they are indefinitely nearing it; this state is called the steady state. This steady state is one for which the system does already not change and remains fixed in its values. When an organism ceases to grow or when an ecosystem has reached its climax, they have reached their steady states. For differential equations (or their sets), this is expressed by equating to zero the derivative(s); the value $y^{*}$ that makes

$$
y^{\prime}=f\left(y^{*} \mid a\right)=0
$$

is the steady state for $y$. For difference equations, the steady state is

$$
y^{*}=y_{t+1}=y_{t} \quad(6)
$$

i.e. the $y$ value remains constant since the instant $t$. It can be calculated from the expression

$$
y^{\prime \prime}=f\left(y^{\prime \prime} \mid a\right)
$$

(cf. Glass and Mackey, 1988). For these two cases, the value $y^{\prime \prime}$ is also called the equilibrium point of $y$ or mode. For linear autonomous and homogeneous equations, there is only one equilibrium point $y^{*}=0$. Non linear equations have more than one equilibrium point. The number of equilibrium points is equal to the degree of the equation; e.g. the logistic differential equation has two equilibrium points $y *_{1}=0$ and $y_{2}=y_{m}$.

Steady states are characterised by their stability or instability. A steady state is stable if the system returns to it after small perturbations. If not, the steady state is unstable. In the former case (stable), the equilibrium point is an attractor and in the latter one (unstable), it is a repeller (cf. Tu, 1994). The behaviour of a system can be studied from a qualitative point of view. These behaviours share similarity; however, specific values of the parameter(s) determine qualitative changes in behaviour and these values are said to be bifurcation points; e.g. for the exponential equation $y^{\prime}=a y$, its equilibrium point is $y^{*}=0$; since $a=0$ determines two kinds of behaviour, it is a bifurcation point; for $a>0, y$ is a repeller and for $a<0, y$ is an attractor.

\section{CHAOS}

Non linear systems can be subjected to chaos. Chaos is a situation placed between absolute order (crystals) and complete disorder (gas; molecular chaos). Predictability is easy for absolute order or complete disorder (Solé and Manrubia, 1996a). In the intermediate situation, predictability is difficult because rules are complex. However, we are in a paradoxical situation since chaos is caused by deterministic processes and originates random products (Smith, 1998). Although chaos theory is a complex subject, some elemental idea can be given about it and there are books such as Smith (op. cit.) with easy expositions.

The first question which arises is about the attractors of a system. Until now, attractors were isolated points, but they can be lines or manifolds. A particular situation is that of a limit cycle. This is frequent in many natural systems; e.g. the predator-prey system in ecology, in which the system oscillates around the same values; these are properties of the Lotka-Volterra differential 
equations; see Margalef (1974). The logistic difference equation $y_{t+1}=a y_{t}\left(1-y_{t}\right)$ shows limit cycles duplicating their period according to increasing values of $a$, determining bifurcations for transitions from one to another; this takes place for $3.0<a<3.57$. As $a \geq 3.57$, there is no stable oscillation and chaos is reached. The logistic difference equation is an example of chaos generated by a discrete dynamic system (cf. Glass and Mackey, 1988). Continuous dynamic systems generate chaos as well.

Chaotic systems are sensitive to initial conditions. This is another of their important traits. In non chaotic systems, small differences in initial conditions; i.e. $y_{0}$ and $y_{0}+\delta y_{0}$, produce convergent trajectories $y$ and $y+\delta y$ as time runs; that is to say, $\delta y \rightarrow 0$ as $t \rightarrow \infty$. In chaotic systems, trajectories diverge exponentially according to the expression

$$
\delta y=\delta y_{0} \exp (\lambda t)
$$

In this equation, $\lambda>0$ it is called the Liapunov exponent.

A third trait for chaos is the character of their attractors. Attractors of non chaotic systems are "normal" (Euclidean) figures. The attractors of chaos are usually intricate; in other words, they are fractal objects and they are called strange attractors.

\section{NATURAL SYSTEMS, BIFURCATIONS AND CHAOS}

Order in natural systems is reached through discontinuous phase transitions with an energy supply. Water passes throughout liquid to ice - ordered solid state - at $\mathrm{t}=0{ }^{\circ} \mathrm{C}$. Progressive cooling needs energy supply in order to pass heat from a cool object to a warmer object, as predicted by the $2^{\text {nd }}$ law of thermodynamics. In biotic systems, however, there is no temperature decrease but a sustained flow of matter and energy; i.e. they are open systems. Order is attained in general when energy producing chaotic movement at microscopic scale (many degrees of freedom) is subjected to constraint at macroscopic scale (few degrees of freedom); car cylinders constrain the movement of a piston produced by an explosion into only one direction (Haken, 1983). This is related to self-organization, since a system deals with external energy and canalises it according to the behaviour of its parts. Thus, from molecular chaos the system would reach order. Morphogenesis or trophic relationships are examples of this.

Bifurcations are relevant for the evolution of a system. Parameters can reach critical values (unstable situations); e.g. let the parameter $a$ and its bifurcation value $a_{c}$; if $a<a_{c}$, the state of the system is $x$ and it is stable. However, a fluctuation around $a_{c}$ may take place by chance. If $a>a_{c}$, a change $x+h$ or $x-h$, with the fluctuation $h$ being very small, leads the system to one mode or to another (see Fig. 2); addition or subtraction of $h$ is at random as well. The system behaves in a determinist way between bifurcations, but at the bifurcation point, there is a stochastic behaviour. Chance

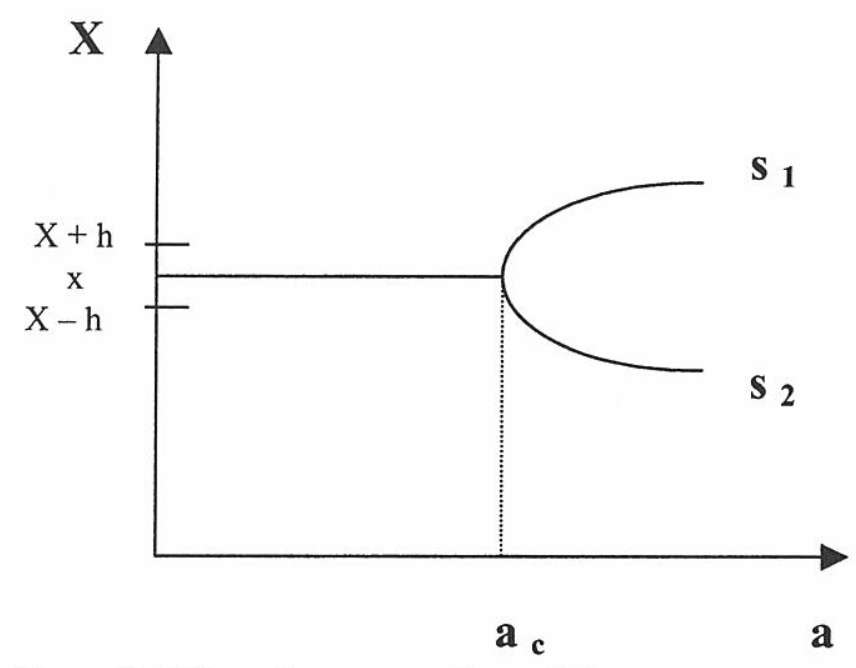

Figure 2. Bifurcations. $a$, value of the parameter; $a_{c}$, bifurcation value; $X$, state of the system; $h$, fluctuation; $s_{l}, s_{2}$, new modes (from Prigogine, 1997).

and necessity play an important role in self-organization processes (Haken, 1983). Figure 3 shows these ideas.

One final remark: time can be inverted in classical mechanics; i.e. $t^{\prime}=-t$. Given an initial condition, a final state can be predicted and inversely, given the final state, it is possible to return to the initial condition. Thus, time would be an illusion (there is no time arrow), as criticised by Prigogine (1997). This is the physical foundation of the uniformitarianism. As said before, Earth and life would have changed, but there would have been no history. Bifurcation introduces history in the system (Prigogine, 1997); therefore, there is a time arrow. As a consequence, the return of professor Ichthyosaur showing a singular Quaternary fossil of a species called Homo sapiens to their students (cf. Gould, 1977) is an impossibility.

If chance is involved at bifurcation points, how is prediction possible? A question can be formulated: has the positive fluctuation the same probability as the negative one? If affirmative, there is no prediction. However, Oster and Alberch (1982) discussed such questions for developmental systems and their evolution. In such systems, inequiprobability is a remarkable trait and it is due to imperfections and anisotropies in the distribution of matter. This makes some kinds of transformations more possible than others for an embryo. The subsequent history of the system has to do with this. Since they considered developing systems as non lineal dynamical systems, these reflections are good for other systems of the same characteristics. Then, inequiprobability permits some kind of prediction (there are modes which are more possible than others).

On the other hand, there are bifurcations leading to chaos, and prediction is obscured again. However, deterministic chaos does not mean whatever point in the phase space but a point to be placed in the limits of a strange attractor. Bifurcation points can be calculated as well. We can find out whether the system is near a bifurcation point or not. 
In conclusion, it is difficult to conceive of a particle palaeontology. There are, of course, two metaphysics involved in our conception of history (human history, social history, and the history of life) that lead to opposite conclusions and, in my view, they would reflect the opposition between capitalism and communism. On the one hand, absolute chance in history has an equivalence with the exclusive occidental individualism assumed by the principles of economic liberalism. On the other hand, the existence of interacting parts and the rise of constraints would be the deterministic counterpart. This would mean historical determinism, a trait of communist ideology. However, neither chance nor necessity are the exclusive rule but a combination of both for the history of systems. Finally, time arrow removes the equivalence of past and future, the foundation of Newtonian physics and uniformitarianism in its substantive meaning. The latter has some theological flavour, because time is always present only for God (Prigogine, 1997).

Evolutionary ideas reflect this dual situation very well. Thompson (1942) and Waddington (1957) criticised variation at random in evolution. Variants would only be ordered and combined by natural selection from their stochastic disordered production. This is a game of trialand-error in which any variant would be tested and selected according to its fitness. The number of dice throws and the time employed would be very large in order to get good adaptive or functional results. In this case, palaeontology has keys to test the main assertion of neodarwinism, as Alberch (1980) showed with the example of the first mammals. Mammiferoid characters appeared independently several times in therapsids during the Triassic. This iterative evolution is a consequence of developmental constraints working on morphological evolution by canalising development; therefore, characters are not independent in their evolution.

\section{PALAEONTOLOGY AND EXTINCTION}

Palaeontology possesses a large mass of evolutionary and palaeoecological data which allows us to understand problems related to extinction processes (cf. Sepkoski, 1997). Now, McKinney (1997) has dealt with extinction vulnerability and he has found selectivity. This refutes particle palaeontology again since species can be removed in function of their traits and certain intervals of geological time are not as good as others for species survival. This is the crucial point for our initial question about palaeontology and its relation to our current environmental problems. Why are certain population more prone to extinction than others? According to McKinney (op. cit), there are two main levels in order to study these questions: an individual level or a population level.

This means a hierarchical point of view because populations consist of organisms and species consist of populations; i.e. they are levels of organization. This immediately suggests the hierarchical expansion of the evolutionary theory in the sense of Vrba and Eldredge

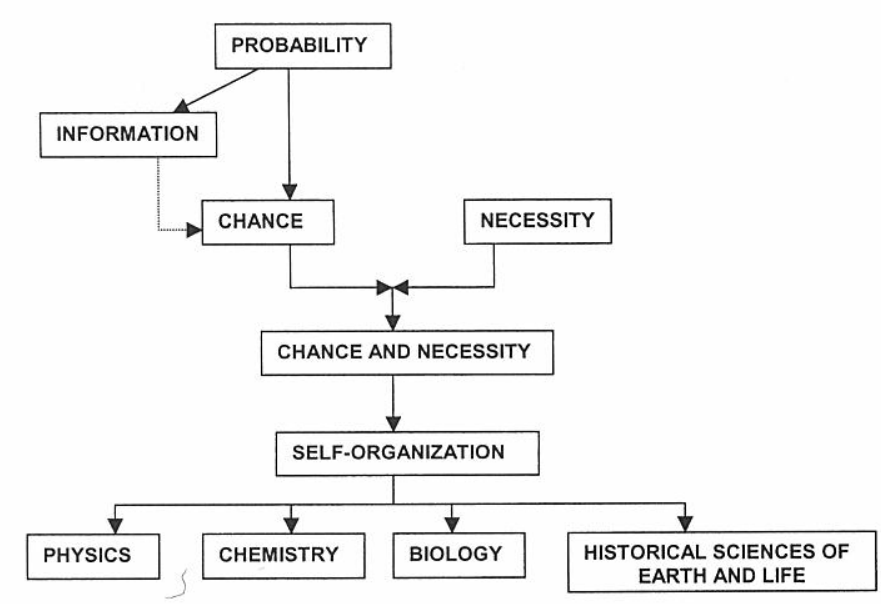

Figure 3. Chance, necessity, self-organization and their relationship with factual sciences (from Haken, 1983, modified).

(1984), Buss (1987) or Vrba (1989). For species or populations, extinction plays the role of organism mortality in classical Darwinism or Neodarwinism. Therefore, extinction can be studied from an evolutionary perspective since it can result from selective processes at different levels. Species selection makes sense when emergent variant properties at the species level interact with the environment in a different way. We could speak about adaptation at the species level (Vrba, 1989; De Renzi, 1989). Thus, the abundance of a species is an emergent trait at the species level. Scarcity leads in general to extinction whereas large population size leads to the survival of species. This is the same for the eurytopic or stenotopic character of species; they are also emergent properties. Species longevity is more frequent in the former than in the latter. On the other hand, organisms with good designs (internal architecture good respiration, efficient excretion -, external functions or behaviour) can favour the species. Variable hereditary traits of organisms are the foundation of the natural selection in Darwinian and Neodarwinian sense and the level is that of the organism; good designs are additive properties for species.

As McKinney (1997) remarks, there can be synergisms among different kinds of traits that promote extinction; e.g. scarcity or stenotopy (populational) and specialization (organismal). Thus, selection at different levels of the genealogical hierarchy can determine the species survival. Since in the last example, specialization is a result of natural selection, a conflict between selection at different levels is produced. Specialization favours organisms, but the presence of specialized organisms does not enhance the survival of species. This conflict between two levels of selection is something recognised by Buss (1987) as frequent in evolutionary processes. Species time spans are palaeontological data and only palaeontology allows us to understand how these synergisms or conflicts took place. Organismal traits are closely related to morphology. The vulnerability of ancient species becomes clear when constraints on evolutionary change are evidenced and functional 
analysis is performed. Functional possibilities in an effective environment are limited by historical and fabricational constraints. This statement is a consequence of the biomorphodynamics approach (Seilacher, 1991a, 1991b). Comparison between preterit and recent species could suggest regularities in order to understand our current environmental problems. Specialization and constraints would be only inferred after biomorphodynamical analysis.

As a consequence of the assumptions of particle palaeontology, any taxon has the same probability of becoming extinct as another. This means an "untaxonbounded" position for evolutionary dynamics (Gould et al., 1977). However, traits leading to extinction are not distributed at random among taxa at different scales according to McKinney (1997), so that species of certain genera are only prone to extinction in mammals and birds.

The internalism-environmentalism dichotomy (Gould, 1977 ) introduces different approaches to extinction. Organic change is partly ruled by extinction and two kinds of extinction are primarily distinguished: mass extinction and background extinction; they have been said to obey two different kinds of mechanisms. The former would be caused by environmental physical impacts (climatic changes, meteoritic impacts, volcanic activity,...) and they have catastrophic character, whereas the latter would be produced by the internal dynamics of the biota, a dichotomy for extinction causes according to the extinction size; i.e. the number of extinct taxa during an interval of geologic time. Therefore, the biota should follow a uniform behaviour in a Lyellian sense, without sudden changes. The latter would be caused by external agents to the biosphere. Although background extinction rates can be variable, as in the Sepkoski (1984) models, they change gently, in a continuous fashion. This picture can only be modified when an external perturbation raises the extinction rate sharply. In this way, Sepkoski (op. cit.) simulated the role of mass extinction in his models. This also obeys the principle by which background extinction is produced by the internal and uniform dynamics of the biota, whereas mass extinction needs physical environmental causes that switch off this parsimonious behaviour.

Another kind of extinction still needs comment: episodic extinction. Episodic extinction is inferred through polycohort (Raup, 1978) or pseudopolycohort (Hoffman and Kitchell, 1984; Raup, 1987) analysis. There are steps of no extinction alternating with more or less intense extinction episodes. If the end of these steps takes place at the same time point for all the cohorts, this is interpreted as a minor environmental crisis troubling the internal mortality pattern. Conodont lineages (De Renzi et al., 1996) during the Triassic show a good example of episodic extinction (Fig. 4).

However, between mass extinction and background extinction there is a continuous spectrum; this was already remarked by Raup and Sepkoski (fide Jablonski, 1986), although Jablonski (op. cit.) continued thinking about mass extinction in terms of patterns quantitatively and

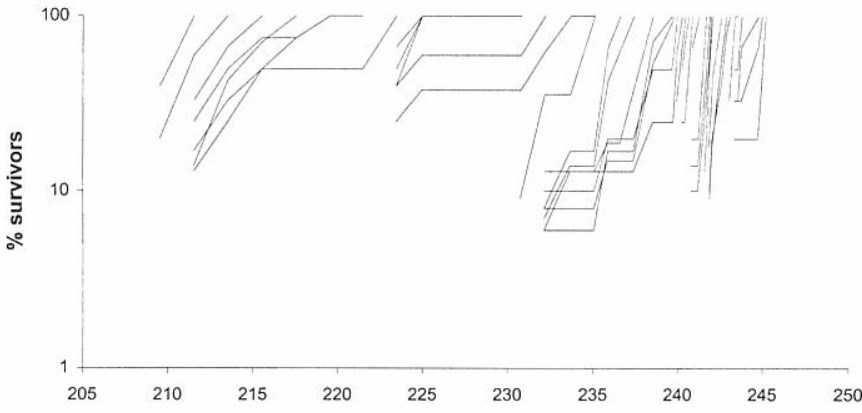

Figure 4. Pseudopolycohort analysis for families of Triassic conodonts; look at the non-extinction steps (synthetic figure summarizing data from De Renzi et al., 1996).

qualitatively different from those of background extinction. This continuum obeys negative power laws, whose model is $f^{-\beta}$, in which $f$ is the extinction size. An example is given by extinction fluctuation for Phanerozoic marine animal genera, with power spectrum $P(f) \propto f^{* \beta}$, with $\beta=0.83 \pm 0.02$. This $\beta$ value is consistent with the hypothesis of free scale laws in nature (Solé et al., 1996, 1997). According to this, mass extinction would be only the outermost case among the oscillating fluctuations of the internal dynamics of the global biota. Extinction patterns show self-similarity in many cases; i.e. they have the same geometry at any temporal scale (Solé et al., 1997) and so they display free scale behaviour.

This shows how major extinctions are very infrequent whereas minor extinctions are very frequent; frequency decreases monotonically with the extinction size. However, there are many monotonic decreasing functions but only negative power functions are free scale laws and they are associated to self-organised criticality (Solé and Manrubia, 1996b), like sand piles, that reach a critical slope and when added new grains can produce collapses in a wide range of size, from only one grain up to a very important amount of sand. Frequency of size obeys negative power law for this typical case of self-organised criticality. For conodont families, I have found they also follow a negative power law for frequency against extinction size (Fig. 5), with $\beta=1.28 \pm 0.12$ (stratigraphic ranges for families come from Aldridge and Smith, 1993). This has been called feeble chaos (Solé et al., 1996). Since they are power laws but not exponential ones, this indicates that extinction and speciation are highly correlated in time and space for the global biota. We can conceive the global biota (or whatever natural system) as a network. These networks have an associated entropy function. Self-organised criticality is related to the entropy maximum (Solé and Manrubia, 1997). On the other hand, an external perturbation could have catastrophic consequences in the vicinity of the system to this critical state (maximal entropy). Therefore, the consequences of a big meteoritic impact could not have been so important if this was produced far from the critical state.

Leakey and Lewin (1997) are afraid that mankind could cause a sixth big extinction. The first question that 


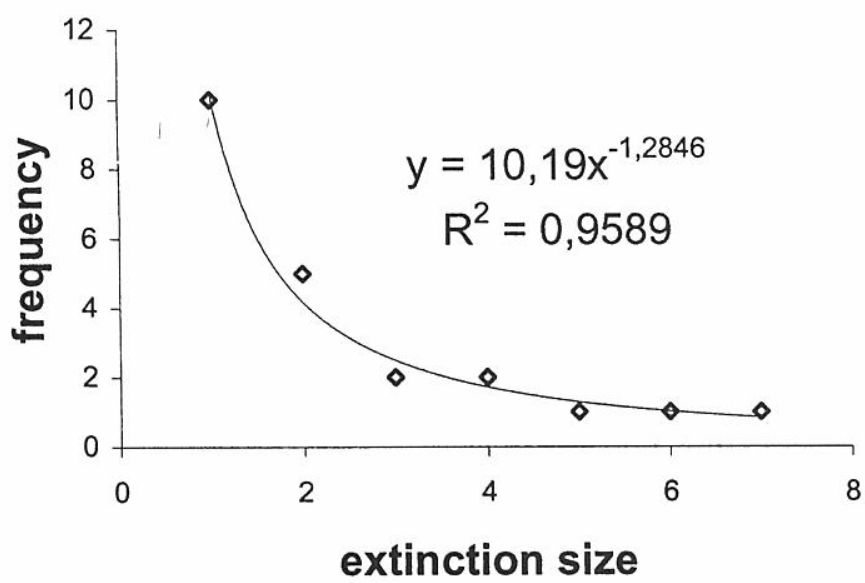

Figure 5. Negative power law for family extinction of conodonts in its whole stratigraphic range.

arises is: Does the biosphere show a similar state to others already repeated and recorded along its history? If the entropy level is similar to one of these states, we should be afraid. In other cases, there are no safe grounds for prediction since local catastrophes are not predictable in deterministic chaos. Since some species are more prone to extinction than others, some predictions might be formulated. McKinney (1997) predicts an impoverishment of biodiversity because the species more prone to extinction will become extinct; as a corollary, the biosphere will become more homogeneous. However, probabilities play a role again, since elimination of extant species or introduction of new ones would be an efficient mechanism for new extinction events that might be independent of direct interactions (Solé et al., 1996). We can see how economies collapse in this unforeseeable way; since economies involve an important network of links, this serves as a good example for my argument.

A final consideration: what happens after extinction? I dealt with this question some years ago (De Renzi, 1988). I remarked that multiple empty niches would trigger new radiations, although diversification would be the more general process without involving any improving adaptive novelty. For such abnormal evolutionary scenario, I proposed sorting processes that are different from natural selection because competition would not be as strong as in normal scenarios. The effect hypothesis (cf. Vrba, 1989) could be one of these mechanisms. To the extent in which the available niches become filled, natural selection would work progressively.

All these questions are related to recovery. Recovery is an evolutionary and ecological process as well. New forms arise and they have morphologies that progressively fill the morphospace. Morphospaces have regions without actual forms because 1) they are not possible ends of developmental pathways or creods or 2) they are non adaptive products (cf. Alberch, 1980; De Renzi, 1988). How are the permitted regions of the morphospace filled? Disparity is not the same as taxonomic richness and disparity can evolve in different ways through geologic time and at different hierarchical levels. There are some relevant questions related to the main purpose of this paper; e.g. Are the initial diversification of form in clades or size variance advantageous for surviving extinctions (Foote, 1997)? On the other hand, perhaps rates of local recovery after extinction are not the reflection of global rates but depend on physical conditions from region to region (Miller, 1998). Physical conditions open the perspective to environmental causes. Careful palaeoecological research can assess the relevance of internal or environmental factors.

\section{CONCLUSIONS}

The main conclusion to be drawn from the preceding discussion is that palaeontology and its data are not the support for a uniformitarian and anhistorical picture of life. A uniformitarian nature would consist of systems that would maintain their reaction capabilities constant (Kauffman, 1988). Palaeontological patterns free of taphonomic noise supply data verifying or falsifying established neontological theories. Neontological theories apply to our moment in time, just as Newtonian mechanics is good for our planet and bodies with low speeds. Nevertheless the latter does not apply to the large spaces of the universe nor velocities close in value to the speed of light. As Simpson (1984) said : “[experimental biology ... and genetics] may reveal what happens to a hundred rats in the course of ten years under fixed and simple conditions, but not what happened to a billion rats in the course of ten million years under the fluctuating conditions of earth history". This was referred to as great scale evolution, but it is also valid for our understanding of the global biota in both temporal and spatial large scales.

Moreover, these palaeontological data and patterns may suggest the need for new kinds of hypothesis. Therefore, palaeontology has keys for the present and for many of the problems that preoccupy mankind. However, our reductionist and mechanicist approaches for nature are insufficient and a systemic focusing is now needed. Newtonian physics, as an exemplary path to follow in science, played an important role in the development of natural history at the beginning of the $\mathrm{XIX}^{\text {th }}$ century. In Paris, the fellows of the Museum looked for exact laws in natural history similar to those attained for physics; this is the case of Cuvier for comparative anatomy (Rudwick, 1972). However, Newtonian physics is fully determinist and mechanicist. Although Newtonian physics supplies the method and the use of mathematics for prediction, nature is neither determinist - in a traditional sense - nor mechanist. The method and mathematics proper for research on natural systems are to be found in the theory of dynamic systems. Real dynamic systems are in general non linear and they can show deterministic chaos. This changes our idea of predictability.

With these tools, relevant contributions of palaeontology may consist of knowing if the current state of the global biota is similar to other older states in which general crisis took place; if these states could be qualified 
in terms of self-organised criticality, and what the role of the physical factors was. Another important contribution of palaeontology would be the accurate knowledge of the behaviour of vulnerable species when self-organised criticality is not yet reached. On the other hand, the physical environment is partly regulated by the global biota. Such is the claim of the Gaia hypothesis (Lovelock, 1983). These questions are important in both theoretical and practical senses, since one of the goals of palaeontology is the dynamics of the global biota throughout its history, but they also have a clarifying function for teaching us how our environment functions and what role a species may play in it -in this case Homo sapiens.

\section{ACKNOWLEDGEMENTS}

I thank Drs. Sixto Fernández (Depto. Paleontología, Universidad Complutense de Madrid) and Leandro Sequeiros (Facultad de Teología, Granada); their review and remarks improved the final version. I thank also Dr. Paul Palmqvist (Depto. de Ecología y Geología, Universidad de Málaga) for his comments. Mr. Owen Palmer (British Council, Valencia) has corrected the English manuscript. This paper has been supported by the DGICYT project PB97-1082.

\section{REFERENCES}

Alberch, P. 1980. Ontogenesis and Morphological Diversification. American Zoologist, 20, 653-667.

Alberch, P. 1991. Del gen al fenotipo: sistemas dinámicos y evolución morfológica. Revista Española de Paleontología, n. extr., 13-19.

Aldridge, J.R. and Smith, M.P. 1993. Conodonta. In: The fossil record 2 (Ed. M.J. Benton. Chapman \& Hall. London, Glasgow, New York, Tokyo, Melbourne, Madras, 563-572.

Bertalanffy, L. v. 1976. Teoría general de los sistemas. Fundamentos, desarrollo, aplicaciones. (Spanish translation of the 1968 book). Fondo de Cultura Económica. México-Madrid-Buenos Aires, 311 pp.

Buss, L.W. 1987. The evolution of individuality. Princeton University Press. Princeton, New Jersey, 203 pp.

Cabezas, E. 1998. El principio de vera causa newtoniano: inspiración "remota" de la selección darwiniana. In: Evolucionismo y racionalismo (Eds. E. Molina, A. Carreras \& J. Puertas). Institución "Fernando el Católico" (CSIC), Excma. Diputación de Zaragoza y Universidad de Zaragoza, 89-100.

De Renzi, M. 1988. What happens after extinction? Revista Española de Paleontología, n. extr., 107-112.

De Renzi, M. 1989. Sobre adaptación y morfogénesis: sus consecuencias micro y macroevolutivas. In: Paleontología. Nuevas tendencias (Ed. E. Aguirre). CSIC, Madrid, 61-81.

De Renzi, M., Budurov, K. and Sudar, M. 1996. The extinction of conodonts - in terms of discrete elements - at the Triassic-Jurassic boundary. Cuadernos de Geología Ibérica, 20, 347-364.

Fernández López, S. 1991. Sistemas tafonómicos: función y evolución. Revista Española de Paleontología, n. extr., 21-34.

Foote, M. 1997. The evolution of morphological diversity. Annual Reviews of Ecology and Systematics, 28, 129. 152.

Glass, L. and Mackey, M.C. 1988. From clocks to chaos. The rhythms of life. Princeton University Press. Princeton, New Jersey, 248 pp.

Gould, S.J. 1967. Is uniformitarianism useful? Reprinted in: Adventures in Earth history (De. P. Cloud). W.H. Freeman and Company, San Francisco and Reading, 51-53.

Gould, S.J. 1977. Eternal metaphors of palaeontology. In: Patterns of evolution, as illustrated by the fossil record (Ed. A. Hallam). Elsevier Publishing Company, Amsterdam, Oxford, New York, pp. 1-26.

Gould, S.J., Raup, D.M., Sepkoski, J.J., Jr., Schopf, T.J.M. and Simberloff, D.S. 1977. The shape of evolution: a comparison of real and random clades. Paleobiology, 3, 23-40.

Haken, H. 1983. Synergetics. An Introduction. Nonequilibrium Phase Transitions and Self-Organization in Physics, Chemistry and Biology. $3^{\text {rd }}$ ed. SpringerVerlag. Berlin, Heidelberg, New York, Tokyo, 371 pp.

Hoffman, A. 1986. Mass extinction, diversification, and the nature of paleontology. Revista Española de Paleontología, 1, 101-107.

Hoffman, A. and Kitchell, J.A. 1984. Evolution in a pelagic planktic system: a paleobiologic test of models of multispecies evolution. Paleobiology, 10, 9-33.

Hooykaas, R. 1970. Continuité et discontinuité en géologie et biologie. Coll. Science ouverte aux Éditions du Seuil, Paris, $366 \mathrm{pp}$.

Jacob, F. 1970. La logique du vivant. Une histoire de l'hérédité. Bibliothèque des Sciences Humaines, nrf, Éditions Gallimard, Paris, 354 pp.

Jablonski, D. 1986. Causes and consequences of mass extinctions: a comparative approach. In: Dynamics of extinction (Ed. D.K. Elliot). John Wiley \& Sons, Inc. New York, 183-229.

Kauffman, E.G. 1988. The dynamic of marine Stepwise Mass Extinction. Revista Española de Paleontología, n. extr., 57-71.

Klir, G.J. 1980. Teoría general de sistemas (Un enfoque metodológico). (Spanish translation of the 1969 book). Ediciones ICE, Madrid, 383 pp.

Leakey, R. y Lewin, R. 1997. La sexta extinción. El futuro de la vida y de la humanidad. Metatemas 50, Tusquets Editores, S.A. Barcelona, 296 pp.

Lovelock, J.E. 1983. Gaia. Una nueva visión de la vida sobre la Tierra (Spanish translation of the 1979 book). Hermann Blume Ediciones, Madrid, 185 pp.

Margalef, R. 1974. Ecología. Ediciones Omega, S.A. Barcelona, $951 \mathrm{pp}$.

McKinney, M.L. 1997. Extinction vulnerability and selectivity: combining ecological and paleontological views. Annual Review of Ecology and Systematics, 28, 495-516. 
Miller, A.I. 1998. Biotic transitions in global marine diversity. Science, 281, 1157-1160.

Oster, G. and Alberch, P. 1982. Evolution and bifurcation of developmental programs. Evolution, 36, 444-459.

Prigogine, I. 1997. Las leyes del caos. Drakontos, Crítica. Grijalbo, Mondadori. Barcelona, 157 pp.

Raup, D.M. 1977. Stochastic models in evolutionary palaeontology. In: Patterns of evolution, as illustrated by the fossil record (Ed. A. Hallam). Elsevier Publishing Company, Amsterdam, Oxford, New York, 59-78.

Raup, D.M. 1978. Cohort analysis of generic survivorship. Paleobiology, 4, 1-15.

Raup, D.M. 1981. Extinction: bad genes or bad luck. Acta Geológica Hispánica, 16, 25-33.

Raup, D.M. 1985. Mathematical models of cladogenesis. Paleobiology, 11, 42-52.

Raup, D.M. 1987. Mass extinction: a commentary. Palaeontology, 30, 1-13.

Rudwick, M.J.S. 1972. The meaning of fossils. Episodes in the history of palaeontology. History of Science Library. Macdonald, London, and American Elsevier Inc., New York, $287 \mathrm{pp}$.

Schopf, T.J.M. 1979. Evolving paleontological views on deterministic and stochastic approaches. Paleobiology, 5, 337-352.

Seilacher, A. 1991a. Self-organizing morphogenetic mechanisms as processors of evolution. Revista Española de Paleontología, n. extr., 5-11.

Seilacher, A. 1991b. Self-Organizing Mechanisms in Morphogenesis and Evolution. In: Constructional Morphology and Evolution (Eds. N. Schmidt-Kittler \& K. Vogel). Springer-Verlag. Berlin, Heidelberg, New York, London, Paris, Tokyo, Hong Kong, Barcelona, Budapest, 251-271.

Sepkoski, J.J., Jr. 1978. A kinetic model of Phanerozoic taxonomic diversity. I. Analysis of marine orders. Paleobiology, 4, 223-251.

Sepkoski, J.J., Jr. 1981. A factor analytic description of the Phanerozoic marine fossil record. Paleobiology, 7, 36-53.

Sepkoski, J.J., Jr. 1984. A kinetic model of Phanerozoic taxonomic diversity. III. Post-Paleozoic families and mass extinctions. Paleobiology, 10, 246-267.

Sepkoski, J.J., Jr. 1990. Evolutionary faunas. In: Palaeobiology. A synthesis (Eds. D.E.G. Briggs \& P.R. Crowther). Blackwell Scientific Publications, Oxford, London, Edinburgh, Boston, Melbourne, Paris, Berlin,
Vienna, 37-41

Sepkoski, J.J., Jr. 1993. Ten years in the library: new data confirm paleontological patterns. Paleobiology, 19, 4351 .

Sepkoski, J.J., Jr. 1997. Biodiversity: past, present and future. Journal of Paleontology, 71, 533-539.

Sequeiros, L. 1999. La epistemología oculta de los paleontólogos. Los fósiles "bajo el crisol de Bacon". Temas Geológico-Mineros ITG, 26, 36-43.

Simpson, G.G. 1984. Tempo and mode in evolution. (Reprint of the 1944 book, with a new introduction by his author). Columbia University Press, New York, 237 pp.

Smith, P. 1998. Explaining chaos. Cambridge University Press. Cambridge (UK), New York, Melbourne, 193 pp.

Solé, R.V. y Manrubia, S.C. 1996a. Orden y caos en sistemas complejos. Ediciones UPC, Universitat Politécnica de Catalunya. Barcelona, 594 pp.

Solé, R.V. and Manrubia, S.C. 1996b. Extinction and selforganized criticality in a model of large-scale evolution. Physical Review E, 54, 42-45.

Solé, R.V. and Manrubia, S.C. 1997. Criticality and unpredictability in macroevolution. Physical Review E, 55, 4500-4507.

Solé, R.V., Bascompte, J. and Manrubia, S.C. 1996. Extinction: bad genes or weak chaos. Proceedings of the Royal Society of London, B 263, 1407-1413.

Solé, R.V., Manrubia, S.C., Benton, M. and Bak, P. 1997. Self-similarity of extinction statistics in the fossil record. Nature, 388, 764-767.

Thompson, D'A.W. 1942. On growth and form (reprinted 1972). Cambridge University Press. London and New York, $1116 \mathrm{pp}$.

Tu, P.N.V. 1994. Dynamical systems. An introduction with applications in economics and biology. $2^{\text {nd }}$ revised and enlarged ed. Springer-Verlag. Berlin, Heidelberg, New York, London, Paris, Tokyo, Hong Kong, Barcelona, Budapest, 314 pp.

Vrba, E.S. 1989. Levels of selection and sorting with special reference to the species level. Oxford Surveys in Evolutionary Biology, 6, 111-168.

Vrba, E.S. and Eldredge, N. 1984. Individuals, hierarchies and processes: towards a more complete evolutionary theory. Paleobiology, 10, 146-171.

Waddington, C.H. 1957. The strategy of the genes. A discussion of some aspects of theoretical biology. George Allen \& Unwin LTD. London, 262 pp. 